\title{
Second Brook Lodge Workshop on Spontaneous Diabetes in Laboratory Animals held at Brook Lodge, Augusta, Michigan, November 6 to 8, 1969 .
}

\section{Introduction by Workshop Editors}

Three years have gone by since the first Brook Lodge Workshop on Spontaneous Diabetes in Laboratory Animals was held and published (DIABETOLOGIA 3, 63-286, 1967). The introduction to the publication of that first Workshop served to define the types of "inherited diabetes", which would be considered, and also to explain why it seemed eminently appropriate to a number of investigators to obtain a fresh view of the problem of diabetes mellitus by making use of the occurrence, in small laboratory animals, of syndromes that exhibit many of the features of human diabetes. The pioneering role of the Jackson Laboratories, in Bar Harbor, Maine, was emphasized and Dr. Margaret M. Dickie, from that institution, was a major contributor to one of the main ends served by the Workshop: that of establishing a common nomenclature acceptable to all participants, representing a majority of the laboratories then working in the field of animal "diabetes".

The second Workshop is first of all a progress report, demonstrating quite clearly the areas where considerable progress has been made, and others where new information has not been forthcoming during the intervening three years. Sadly, Dr. Margaret Dickie did not attend the second Workshop, a brief and sudden illness having resulted in her unexpected death, at the age of 47, on July 4, 1969. Because of her major contributions to research on mutant mice and her discovery of many naturally occurring mutant strains of mice, several of which now serve as animal models of human disease, as well as because of her particular involvement throughout the early phases of work on mutant mice with anomalies of blood glucose homeostasis and of energy storage, the participants in the second Workshop expressed the unanimous wish that the publication of the Workshop be dedicated to her. This the Workshop Editors are very pleased to do.

Dr. Margaret $M$. Dickie was born at Washington, Pennsylvania, in January 1922. She received her bachelor's degree from Mount Holyoke College in 1943, her master's degree from the University of Maine in 1946, and her Ph. D. from Brown University in 1958. She began a career in biological research at the Jackson Laboratory in 1942 while still a student, and continued her association with the mammalian genetics research center of that laboratory without interruption from then on. Her research concerned spontaneous mutation rates in mice, new neuromuscular and neurological mutations in mice, as well as mutations associated with obesity and inappropriate hyperglycemia, and the propagation of dominant lethal mutations in the mouse. She has also served as supervisor of genetic quality control for the Jackson Laboratory since 1962, a function involving the monitoring of the genetic characteristics of the two million inbred, mutant, and hybrid mice produced by the Jackson Laboratory each year for use in international biomedical research.

Dr. Dickie was a member of the American Association for the Advancement of Science, the Genetics Society of America, the American Society of Zoologists, the American Genetics Association, and the Association for Cancer Research. She served on the editorial board of the Journal of Heredity from 1965 until her death. She published 60 scientific articles during her research career.

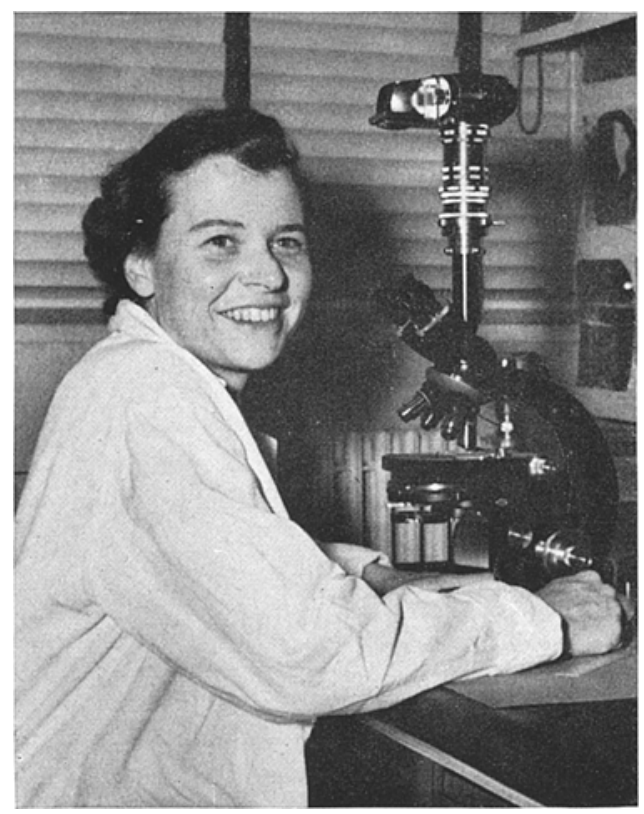

In making major contributions to the field of genetics in mice, with special emphasis on mutations and the use of specific mutants for biomedical research, Dr. Dickie has helped all research workers principally interested in developing models of human diseases in order to understand better their etiology and pathogenesis. Her contributions have particularly helped the field of diabetes-related research and almost all workers interested in genetics in the mouse and the availability of disease models in that species have, at one time or another, greatly benefited by correspondence or personal discussions with Dr. Dickie, who enjoyed teaching, explaining, and most generously helping those less expert in her field. It is indeed appropriate that the second Brook Lodge Workshop on Spontaneous Diabetes in Laboratory Animals be dedicated to her memory.

Albert E. Renold, Geneva

George F. Cahill, Jr., Boston

George C. Gerritsen, Kalamazoo 